\title{
The short-term, genome-wide effects of indirect selection deserve study: a response to Charlesworth and Jensen (2022)
}

\author{
Zachariah Gompert ${ }^{1}$, Jeff Feder ${ }^{2}$, and Patrik Nosil ${ }^{3}$ \\ ${ }^{1}$ Utah State University \\ ${ }^{2}$ U. Notre Dame \\ ${ }^{3}$ Affiliation not available
}

February 2, 2022

\begin{abstract}
We recently published a paper quantifying the genome-wide consequences of natural selection, including the effects of indirect selection due to the correlation of genetic regions (neutral or selected) with directly selected regions (Gompert et al. 2022). In their critique of our paper, Charlesworth \& Jensen (2022) make two main points: (i) indirect selection is equivalent to hitchhiking and thus well documented (i.e., our results are not novel), and (ii) that we do not demonstrate the source of linkage disequilibrium (LD) between SNPs and the Mel-Stripe locus in the Timema cristinae experiment we analyze. As we discuss in detail below, neither of these are substantial criticisms of our work.
\end{abstract}

\section{Hosted file}

CharlesworthResponse_manuscript.pdf available at https://authorea.com/users/334689/articles/ 555118-the-short-term-genome-wide-effects-of-indirect-selection-deserve-study-aresponse-to-charlesworth-and-jensen-2022 